\title{
Application of artificial intelligence to estimate the reference evapotranspiration in sub-humid Doon valley
}

\author{
Manish K. Nema ${ }^{1}$ Deepak Khare ${ }^{2} \cdot$ Surendra K. Chandniha ${ }^{1}$
}

Received: 18 May 2016/Accepted: 13 February 2017/Published online: 2 March 2017

(c) The Author(s) 2017. This article is published with open access at Springerlink.com

\begin{abstract}
Estimation of evapotranspiration (ET) is an essential component of the hydrologic cycle, which is also requisite for efficient irrigation water management planning and hydro-meteorological studies at both the basin and catchment scales. There are about twenty wellestablished methods available for ET estimation which depends upon various meteorological parameters and assumptions. Most of these methods are physically based and need a variety of input data. The FAO-56 PenmanMonteith method (PM) for estimating reference evapotranspiration $\left(\mathrm{ET}_{0}\right)$ is recommend for irrigation scheduling worldwide, because PM generally yields the best results under various climatic conditions. This study investigates the abilities of artificial neural networks (ANN) to improve the accuracy of monthly evaporation estimation in sub-humid climatic region of Dehradun. In the first part of the study, different ANN models, comprising various combinations of training function and number of neutrons were developed to estimate the $\mathrm{ET}_{0}$ and it has been compared with the Penman-Monteith (PM) $\mathrm{ET}_{0}$ as the ideal (observed) $\mathrm{ET}_{0}$. Various statistical approaches were considered to estimate the model performance, i.e. Coefficient of Correlation $(r)$, Sum of Squared Errors, Root Mean Square Error, Nash-Sutcliffe Efficiency Index (NSE) and Mean Absolute Error. The ANN model with Levenberg-Marquardt training algorithm, single hidden layer and nine number of neutron schema was found the best predicting capabilities for the study station with Coefficient of Correlation $(r)$ and NSE
\end{abstract}

Manish K. Nema

mxnema@gmail.com

1 National Institute of Hydrology, Roorkee, India

2 WRDM, Indian Institute of Technology, Roorkee, India value of 0.996 and 0.991 for calibration period and 0.990 and 0.980 for validation period, respectively. In the subsequent part of the study, the trend analysis of $\mathrm{ET}_{0}$ time series revealed a rising trend in the month of March, and a falling trend during June to November, except August, with more than 90\% significance level and the annual declining rate was found to $1.49 \mathrm{~mm}$ per year.

Keywords Evapotranspiration · Penman-Monteith · Neural networks · Mann-Kendall test

\section{Introduction}

Evapotranspiration (ET) is one of the major components to identify the behaviour of hydrologic cycle. Correct estimation of reference evapotranspiration $\left(\mathrm{ET}_{0}\right)$ is necessary for determining irrigation demands, irrigation scheduling, water resources management, and environmental impact assessment, water balance studies at regional and local levels, and modelling of various rainfall-runoff and ecosystem models. Further, the actual ET can be determined using crop coefficients, which is mainly a function of various crop characteristics and local environmental conditions. This paper deals only with the estimation of $\mathrm{ET}_{0}$. Inaccurate estimates of $\mathrm{ET}_{0}$ can lead to unproductive use of water, false calibrations of hydrological models, and erratic assessments of groundwater recharge. There are many empirical equations available for estimating $\mathrm{ET}_{0}$, but their cogency is sometimes restricted to particular geographic locations or/and specific climatic conditions. Allen et al. (1998) defined $\mathrm{ET}_{0}$ as "the rate of evapotranspiration from a hypothetical crop with an assumed crop height $(0.12 \mathrm{~m})$ and a fixed canopy resistance $(70 \mathrm{~s} / \mathrm{m})$ and albedo 
(0.23) which would closely resemble evapotranspiration from an extensive surface of green grass cover of uniform height, actively growing, completely shading the ground and not short of water. The Food and Agriculture Organization (FAO) of the United Nations recently adopted a standardized form of the Penman-Monteith equation (FAO56 PM) in an effort to provide a common, globally valid standard for estimating $\mathrm{ET}_{0}$, developing crop coefficients, and evaluation/calibration of other $\mathrm{ET}_{0}$ methods when Lysimeter measurements are unavailable (Allen et al. 1998). There are more than twenty established methods available for estimating of ETO, these can be broadly classified into three groups temperature-based approaches (i.e. Hargreaves-Samani and Thornthwaite), radiation based approaches (i.e. Priestley-Taylor and Turc) and combination approach (i.e. Penman-Monteith). Most of these methods are physically based and need a variety of input data.

Apart from the tradition modeling techniques, artificial intelligence techniques such as artificial neural networks (ANNs), have proven their feasibility in modeling complex nonlinear phenomena in the recent past (Kumar et al. 2002; Kisi 2006a, b; Rahimikhoob 2010; Kumar et al. 2011; Baba et al. 2013; Goyal et al. 2014; Shamshirband et al. 2015). ANN application to ET modeling initiated when Odhiambo et al. (2001) validated the accurate estimate daily $\mathrm{ET}_{0}$ with the fuzzy $\mathrm{ET}_{0}$ models when compared with FAO56 PM. Further, Kumar et al. (2002) reported the precise $\mathrm{ET}_{0}$ estimations using the developed ANN models with various ANN architectures.

It has been demonstrated that neural networks are a competitive substitute to conventional models for modeling nonlinear systems. Recently, artificial neural networks (ANN) have been applied in meteorological and agroecological modelling; most of the applications reported in the literature concern estimation, prediction and classification problems (Dogan 2008; Kim and Kim 2008; Parasuraman et al. 2007; Zanetti et al. 2007; Keskin and Terzi 2006; Sudheer et al. 2003; Trajkovic et al. 2003). Neural network applications have gained popularity due to their functional characteristics, lesser data requirement and capability of long term forecasting which provide many advantages over traditional analytical approaches. There has been a rising drift of application of ANNs in water resources and hydrologic modeling. The basic goal of this paper is to evaluate the comparative performance of ANN based approach with the Penman-Monteith method (Allen et al. 1998) for estimating the $\mathrm{ET}_{0}$ on monthly basis. The trend analysis along with the magnitude of trend of $\mathrm{ET}_{0}$ for the period of 34 years also has been done for the study station located at Doon valley of Shivaliks hills.

\section{Materials and methods}

\section{Study area and data used}

Monthly climatic data used for $\mathrm{ET}_{0}$ estimation were acquired from meteorological observatory from Forest Research Institute (FRI), Dehradun. The observatory is located in the Doon Valley of Shivaliks range of the Himalayas. Its geographical location is $30.20 \mathrm{~N}$ latitude and 77.59 E longitude. Dehradun has an altitude of $629 \mathrm{~m}$ above mean sea level. It has sub-humid, sub-tropic climate. The summer is too humid and hot, the winter is too cold and the rainy season has a heavy rainfall. The monthly mean of maximum temperature lies in the range of 18.6-38.6 ${ }^{\circ} \mathrm{C}$. The minimum temperature varies between 1.7 and $23.4{ }^{\circ} \mathrm{C}$. June is the hottest and January is the coolest month. The monsoon season experiences about $87 \%$ of the average annual rainfall of about $2041.9 \mathrm{~mm}$. Location map of study area is shown in Fig. 1.

While modeling, the monthly temperature (Min., Max., and Avg.), relative humidity (Min. and Max.), average wind speed, sunshine hours and rainfall data from 1980 to 2013 (i.e. 408 datasets) were divided into calibration period 1980-2004 (300 datasets) and validation period 2005-2013 (108 datasets).

\section{Penman-Monteith method}

Penman-Monteith (PM) FAO56 method for estimating $\mathrm{ET}_{0}$ is a physically based method that unambiguously integrates both physiological and aerodynamic parameters (Xu et al. 2006). It is supposed to be the most consistent and worldwide accepted method for $\mathrm{ET}_{0}$ estimation under various types of climate. The most common form of the $\mathrm{PM}$ method in computing $\mathrm{ET}_{0}$ is given as (Allen et al. 1998):

$\mathrm{ET}_{0}=\frac{0.408 \Delta\left(R_{\mathrm{n}}-G\right)+\gamma \frac{900}{T+273} u_{2}\left(e_{s}-e_{a}\right)}{\Delta+\gamma\left(1+0.34 u_{2}\right)}$

where $\mathrm{ET}_{0}$ is the reference evapotranspiration ( $\mathrm{mm} /$ day); $R_{\mathrm{n}}$ is the net radiation at the crop surface $\left(\mathrm{MJ} / \mathrm{m}^{2} / \mathrm{d}\right)$; $G$ is the soil heat flux density $\left(\mathrm{MJ} / \mathrm{m}^{2} / \mathrm{d}\right) ; T$ is the mean daily air temperature $\left({ }^{\circ} \mathrm{C}\right) ; u_{2}$ is the wind speed at a $2 \mathrm{~m}$ height above the ground $(\mathrm{m} / \mathrm{s}) ; e_{s}$ is the saturation vapour pressure $(\mathrm{kPa}) ; e_{a}$ is the actual vapour pressure $(\mathrm{kPa}) ; e_{s}-e_{a}$ is the saturation VPD $(\mathrm{kPa}) ; \Delta$ is the slope of vapour pressure versus temperature curve at temperature $T\left(\mathrm{kPa} /{ }^{\circ} \mathrm{C}\right)$, and $\Upsilon$ is the psychrometric constant $\left(\mathrm{kPa} /{ }^{\circ} \mathrm{C}\right)$. The reference crop was assumed as green grass with an albedo of 0.23 . 


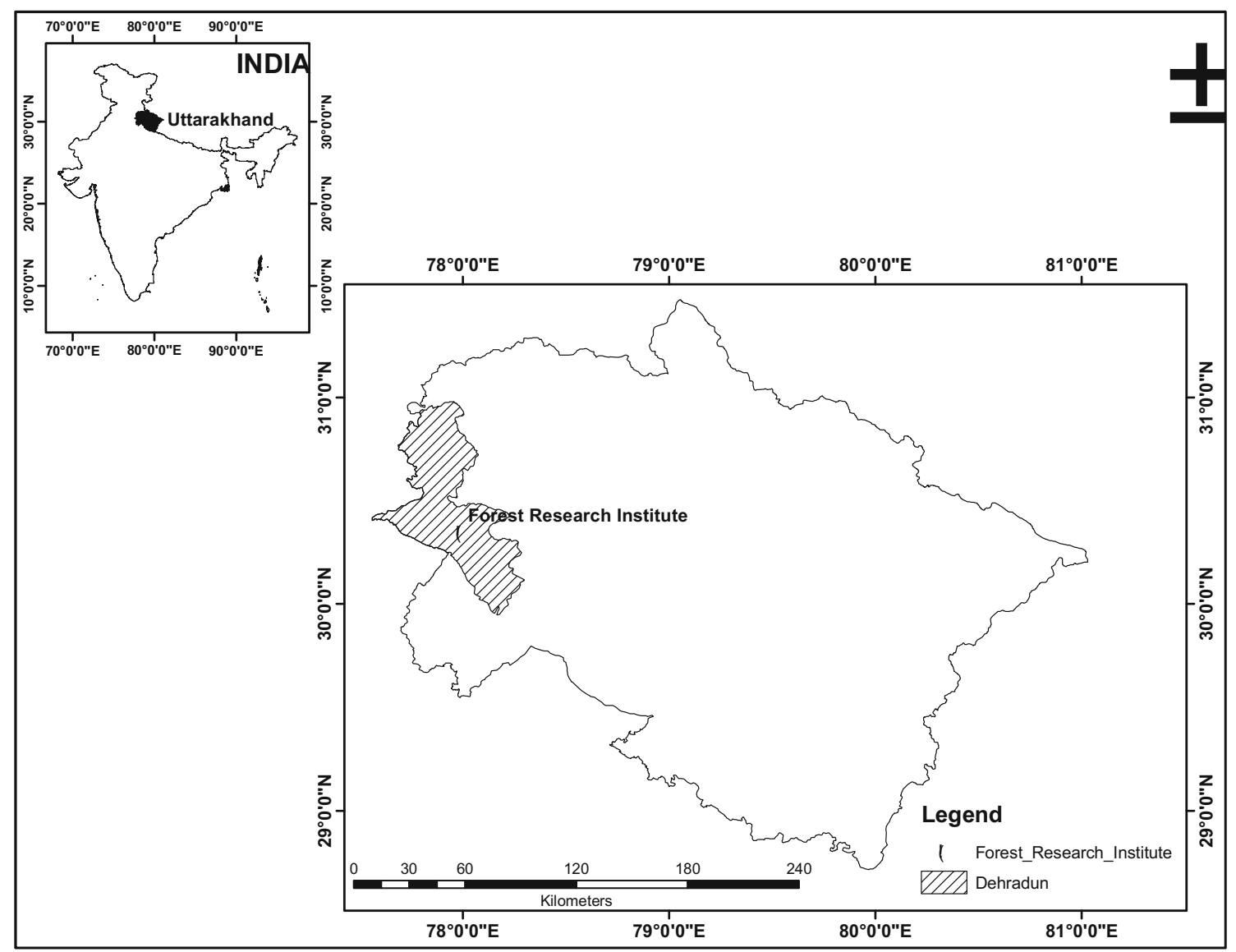

Fig. 1 Location map of study area

\section{Artificial neural networks (ANNs)}

Commonly an ANN architecture consist of a set of the artificial neuron inputs or signals $(x)$, a weighted average calculation of them $(z)$ using the summation function and weights $(w)$, and some activation function $(f)$ to produce an output, where

$Z=\sum_{i=1}^{n} x_{i} w_{i}$

The connections between the input layer and the middle or hidden layer contain weights [Eq. (2)], which are usually determined through training the system. The hidden layer sums the weighted inputs and uses the transfer function to create an output value. The transfer function is a relationship between the internal activation level of the neuron (called activation function) and the outputs. A typical transfer function is the sigmoid function, which varies from 0 to 1 for a range of inputs (Melesse et al. 2011). The 408 dataset was divided into training and validation data (300 training and 108 validations) for single hidden layer in three-layer feed forward back propagation algorithm. The feed forward back propagation algorithms was applied using different transfer function and best transfer function (logsig) is chosen on the basis of performance of model. The supervised learning of model is done using reference evapotranspiration $\left(\mathrm{ET}_{0}\right)$ as output and temperature (Min., Max., and Avg.), relative humidity (Min. and Max.), average wind speed, and sunshine hours as input parameters.

\section{Levenberg-Marquardt back propagation}

The Levenberg-Marquardt also known as the damped least-squares (DLS) method is used to solve non-linear least squares problems. It is a trust region-based method with a hyper-spherical trust region (Ajmera and Goyal 2012; Kumar et al. 2015). The Levenberg-Marquardt algorithm uses this approximation to the Hessian matrix in the following Newton-like update

$X_{k+1}=X_{k}-\left[J_{k}^{T} J+\mu I\right]^{-1} J^{T} e$

where $J=$ Jacobian matrix, which contains the first derivatives of the network errors regarding the weights and biases; $e=$ vector of network errors; and $I=$ identity matrix. 
When the scalar $\mu$ is zero, this is just a Newton's method, using the approximate Hessian matrix. When $\mu$ is large, this becomes gradient descent with a small step size. Newton's method is faster and more accurate near an error minimum, so the aim is to shift toward Newton's method as quickly as possible (Hagan and Menhaj 1994 and MATLAB online reference manual). Thus, $\mu$ is decreased after each successful step (reduction in performance function) and is increased only when a tentative step would increase the performance function.

Goodness of fit of model performance The performance of the any model can be evaluated in terms of variety of statistical criteria. However, four standard statistical evaluation criteria, viz. Coefficient of Correlation $(r)$, Sum of Squared Errors (SSE), Root Mean Square Error (RMSE), Nash-Sutcliffe Efficiency Index (NSE) and Mean Absolute Error (MAE) were used to measure the performance of models (Moriasi et al. 2007).

1. Coefficient of correlation $(r)$

$$
r=\frac{n\left(\sum x_{0} \times x_{f}\right)-\left(\sum x_{0}\right) \times\left(\sum x_{f}\right)}{\sqrt{\left[n \sum x_{0}^{2}-\left(\sum x_{0}\right)^{2}\right]\left[n \sum x_{f}^{2}-\left(\sum x_{f}\right)^{2}\right]}}
$$

where $x_{0}=$ observed data, $x_{f}$ computed data, $n=$ total number of events considered.

2. Sum of Squared Errors (SSE)

$$
\mathrm{SSE}=\sum_{i=1}^{n}\left(x_{0}-\bar{x}\right)^{2}
$$

where $x_{0}=$ observed data, $x_{f}$ computed data.

3. Nash-Sutcliffe Efficiency (NSE):

$\mathrm{NSE}=1-\frac{\sum_{i=1}^{n}\left(x_{0}-x_{f}\right)^{2}}{\sum_{i=1}^{n}\left(x_{0}-\bar{x}_{0}\right)^{2}}$

where $x_{0}=$ observed data, $x_{f}$ computed data, $\bar{x}=$ mean of the observed data, and $n=$ total number of events considered.

\section{Mean Absolute Error (MAE)}

$\mathrm{MAE}=1-\frac{\sum_{i=1}^{n}\left|x_{0}-x_{f}\right|}{N}$

where $x_{0}=$ observed data, $x_{f}$ computed data, $\bar{x}=$ mean of the observed data, and $N=$ number of non-missing data points.

\section{Trend analysis}

The trend detection in the $\mathrm{ET}_{0}$ time series of the FRI, Dehradun station has been done using the most commonly used nonparametric Mann-Kendall (MK) and Modified Mann-Kendall (MMK) test (Mann 1945; Kendall and Stuart 1961; Kendall 1962). It is a rank-based technique, which is good enough to accommodate the effect of intermediate extremes events and take cares of the skewed variables. The rate of the change in the time series at the said station has also been determined with Sen' Slope estimator method (Sen 1968). According to this test, the null hypothesis $\mathrm{H}_{0}$ states that the de-seasonalized data $\left(x_{1} \ldots x_{n}\right)$ is a sample of $n$ independent and identically distributed random variables. The alternative hypothesis $\mathrm{H}_{1}$ of a two-sided test is that the distributions of $x_{k}$ and $x_{j}$ are not identical for all $k$, $j \leq n$ with $k \neq j$. The test statistic $S$, which has mean zero and a variance computed by Eq. (4), is calculated using Eqs. (2) and (3), and is asymptotically normal (Hirsch et al. 1982):

$S=\sum_{k=1}^{n-1} \sum_{j=k+1}^{n} \operatorname{sgn}\left(x_{j}-x_{k}\right)$

$\operatorname{Sgn}\left(x_{j}-x_{k}\right)= \begin{cases}+1 & \text { if }\left(x_{j}-x_{k}\right)>0 \\ 0 & \text { if }\left(x_{j}-x_{k}\right)=0 \\ -1 & \text { if }\left(x_{j}-x_{k}\right)<0\end{cases}$

$\operatorname{Var}(S)=\left[n(n-1)(2 n+5)-\sum_{t} t(t-1)(2 t+5)\right] / 18$

The notation $t$ is the extent of any given tie and $\sum_{t}$ denotes the summation over all ties. In cases where the sample size $n>10$, the standard normal variate $z$ is computed using Eq. (5). In a two-sided test for trend, $H_{0}$ should thus be accepted if $|z| \leq z_{\alpha / 2}$ at the $\alpha$ level of significance. A positive value of ' $S$ ' indicates an 'upward trend'; likewise, a negative value of ' $S$ ' indicates 'downward trend':

$Z_{m k}= \begin{cases}\frac{S-1}{\sqrt{\operatorname{Var}(S)}} & \text { if } S>0 \\ 0 & \text { if } S=0 \\ \frac{S-1}{\sqrt{\operatorname{Var}(S)}} & \text { if } S<0\end{cases}$

The Mann-Kendall test has two parameters that are of importance to trend detection. These parameters are the significance level that indicates the trends strength and the slope magnitude estimates that indicates the direction as well as the magnitude of the trend. The MK test checks the null hypothesis of no trend versus the alternative hypothesis of the existence of increasing or decreasing trend. If $Z_{m k}$ is positive, then the trend is increasing, and if $Z_{m k}$ is negative, then the trend is decreasing. 


\section{Trend analysis using the MMK test}

The modified Mann-Kendall test is similar to MK test, except the effect of all significant autocorrelation coefficients has to be removed from the time series (Hamed and Rao 1998; Basistha et al. 2009) and its empirical significance level are more accurate. For this purpose, a modified variance of $\mathrm{S}$, designated as $\operatorname{Var}(S)^{*}$, was used as follows:

$\operatorname{Var}(S)^{*}=V(S) \frac{n}{n^{*}}$

where $n^{*}=$ effective sample size. The $n / n^{*}$ ratio was computed directly from the equation proposed by Hamed and Rao (1998) as

$$
\begin{aligned}
\frac{n}{n^{*}}= & 1+\frac{2}{n(n-1)(n-2)} \sum_{i=1}^{n-1} \\
& (n-i)(n-i-1)(n-i-2) \gamma_{i}
\end{aligned}
$$

where $n=$ actual number of observations, and $r i=$ lag$i$ significant auto coefficient of correlation of rank $i$ of time series. Once $\operatorname{Var}(S)^{*}$ was computed from Eq. (6), then it was substituted for $\operatorname{Var}(S)$ in Eq. (5). The estimate $Z$-values is then tested for significance of trend. The normal threshold levels, for various significance levels are as follows: 1.645 for $10 \%, 1.96$ for $5 \%$ and 2.33 for $1 \%$ level of significance.

\section{Magnitude of the trend}

The magnitude of the trend or the rate of change in a time series was estimated using a non-parametric Sen's slope estimator method (Sen 1968). In this method, a linear trend in the time series is generally assumed and the slope $\left(T_{i}\right)$ of all pairs are first calculated by

$T_{i}=\frac{x_{j}-x_{k}}{j-k} \quad$ for, $i=1,2,3 \ldots N$

where $X_{j}$ and $X_{k}$ area data values at time $j$ and $k(j>k)$, respectively. The median of these $N$ values of $T_{i}$ is Sen's estimator of slope which is calculated as

$\beta= \begin{cases}T_{\frac{N+1}{2}} & N \text { is odd } \\ \frac{1}{2}\left(T_{\frac{N}{2}}+T_{\frac{N+2}{2}}\right) & N \text { is even }\end{cases}$

The trend is supposed to be upward (increasing) with positive values of $B$ and vice versa.

\section{Result and discussion}

\section{ANN model for $\mathbf{E T}_{\mathbf{0}}$}

Initially the ANN Models have been tested with the different training algorithm and six numbers of neurons and single hidden layer. To get the more accurate ANN model the performance of six predictive training algorithms was evaluated (Table 1) while developing the model itself. The most promising training algorithm in the hidden layer of ANN model was determined by trial and error, at which a model perform better.

Table 1 indicates that model with training algorithm Levenberg-Marquardt algorithm (trainlm) resulted satisfactory value of coefficient of correlation $(r)$ as 0.997 and 0.989 during training and validation, respectively. The figures in bold represents the best performing indicies. The model performance indices; SSE and RMSE with scaled estimate and target is lowest as 0.733 and 0.049 for training and 1.102 and 0.101 for validation periods, respectively. Predictive power of ANN models, i.e. NSE has been worked out and found highest as 0.994 and 0.978 for training and validation runs, respectively, for model with trainlm function. MAE was found lowest in case tarincgf function. Based on the four out of five performance indices the trainlm function was chosen for further modeling.

Increasing the number of neurons in the hidden layer, the network gets an over fit, that problem has to be resolved. To get the optimum number of neurons at which network should have to perform its best, trial and error method has been applied. Optimization of the number of neurons for further modeling exercise is one of the most crucial part of any ANN model development. The model with learning function "trainlm" trained with $75 \%$ of data has been assessed for optimum number of neurons. Neurons in the intermediate hidden layer have been varied from 1 to 10 . The comparison of different performance parameters presented in Table 2 for the neuron variation. It can be identified that model with "trainlm" algorithm and nine neurons performed best for the validation results for most of the statistical indices. Scatterplots between observed (FAO56-PM) and modelled (ANN) $\mathrm{ET}_{0}$ for validation and calibration runs can be shown in Fig. 2 demonstrating the model performance. It can be observed from these scatterplots that ANN model has a strong predictive power for the given data sets and $\mathrm{ET}_{0}$ for the FRI, station Dehradun ranges from 2.4 to $5.0 \mathrm{~mm} /$ day.

The values of mean monthly FAO-PM $\mathrm{ET}_{0}$ and predicted $\mathrm{ET}_{0}$ with the ANN model with "trainlm" training algorithm at nine neurons can be compared as shown in Table 3. It can be perceived that the value of $\mathrm{ET}_{0}$ for the pre-monsoon months, i.e. summer season is higher due to hot and humid weather conditions and the lowest $\mathrm{ET}_{0}$ values were appearing during the winter months. The total annual $\mathrm{ET}_{0}$ was observed to be $1300.85 \mathrm{~mm}$. And it is found comparable and close to the model predicted annual $\mathrm{ET}_{0}$ value of $1306.55 \mathrm{~mm}$. Figure 3 represents the basic statistic of $\mathrm{ET}_{0}$ for the study period of 34 years (1980-2013) in the form of box plot. 
Table 1 Performance of different training algorithms for ANN based $\mathrm{ET}_{0}$ modeling

\begin{tabular}{|c|c|c|c|c|c|c|c|c|c|c|c|}
\hline \multirow[t]{2}{*}{$\mathrm{SN}$} & \multirow[t]{2}{*}{ Training functions } & \multicolumn{5}{|c|}{ Training } & \multicolumn{5}{|c|}{ Validation } \\
\hline & & $r$ & SSE & RMSE & NSE & MAE & $r$ & SSE & RMSE & NSE & MAE \\
\hline 1 & trainbfg & 0.997 & 0.785 & 0.051 & 0.994 & 0.926 & 0.983 & 1.760 & 0.128 & 0.964 & 0.873 \\
\hline 2 & trainbr & 0.997 & 0.851 & 0.053 & 0.993 & 0.922 & 0.976 & 2.508 & 0.152 & 0.949 & 0.861 \\
\hline 3 & traincgb & 0.996 & 1.090 & 0.060 & 0.991 & 0.913 & 0.988 & 1.233 & 0.107 & 0.975 & 0.878 \\
\hline 4 & traincgf & 0.992 & 2.088 & 0.083 & 0.983 & 0.876 & 0.969 & 3.047 & 0.168 & 0.938 & 0.843 \\
\hline 5 & traincgp & 0.994 & 1.413 & 0.069 & 0.989 & 0.903 & 0.977 & 2.315 & 0.146 & 0.953 & 0.885 \\
\hline 6 & trainlm & 0.997 & 0.733 & 0.049 & 0.994 & 0.930 & 0.989 & 1.102 & 0.101 & 0.978 & 0.866 \\
\hline
\end{tabular}

Table 2 Performance of ANN model with the varied number of neurons

\begin{tabular}{|c|c|c|c|c|c|c|c|c|c|c|c|}
\hline \multirow[t]{2}{*}{ SN } & \multirow[t]{2}{*}{ No. of neurons } & \multicolumn{5}{|c|}{ Training } & \multicolumn{5}{|c|}{ Validation } \\
\hline & & $r$ & SSE & RMSE & NSE & MAE & $r$ & SSE & RMSE & NSE & MAE \\
\hline 1 & 1 & 0.979 & 5.161 & 0.131 & 0.958 & 0.814 & 0.976 & 2.909 & 0.164 & 0.941 & 0.809 \\
\hline 2 & 2 & 0.990 & 2.564 & 0.092 & 0.979 & 0.869 & 0.968 & 3.341 & 0.176 & 0.932 & 0.843 \\
\hline 3 & 3 & 0.994 & 1.413 & 0.069 & 0.989 & 0.908 & 0.958 & 4.391 & 0.202 & 0.911 & 0.838 \\
\hline 4 & 4 & 0.996 & 0.976 & 0.057 & 0.992 & 0.917 & 0.978 & 2.399 & 0.149 & 0.951 & 0.841 \\
\hline 5 & 5 & 0.995 & 1.369 & 0.068 & 0.989 & 0.904 & 0.941 & 6.314 & 0.242 & 0.872 & 0.828 \\
\hline 6 & 6 & 0.995 & 1.369 & 0.068 & 0.989 & 0.904 & 0.941 & 6.314 & 0.242 & 0.872 & 0.828 \\
\hline 7 & 7 & 0.995 & 1.369 & 0.068 & 0.989 & 0.904 & 0.941 & 6.314 & 0.242 & 0.872 & 0.828 \\
\hline 8 & 8 & 0.997 & 0.776 & 0.051 & 0.994 & 0.929 & 0.965 & 3.530 & 0.181 & 0.929 & 0.852 \\
\hline 9 & 9 & 0.996 & 1.155 & 0.062 & 0.991 & 0.910 & 0.990 & 0.978 & 0.095 & 0.980 & 0.882 \\
\hline 10 & 10 & 0.997 & 0.848 & 0.053 & 0.993 & 0.926 & 0.978 & 2.229 & 0.144 & 0.955 & 0.865 \\
\hline
\end{tabular}

Fig. 2 Performance of ANN model with "trainlm" training algorithm at nine neurons for $\mathrm{ET}_{0}$ estimation for calibration (left) and validation (right) runs
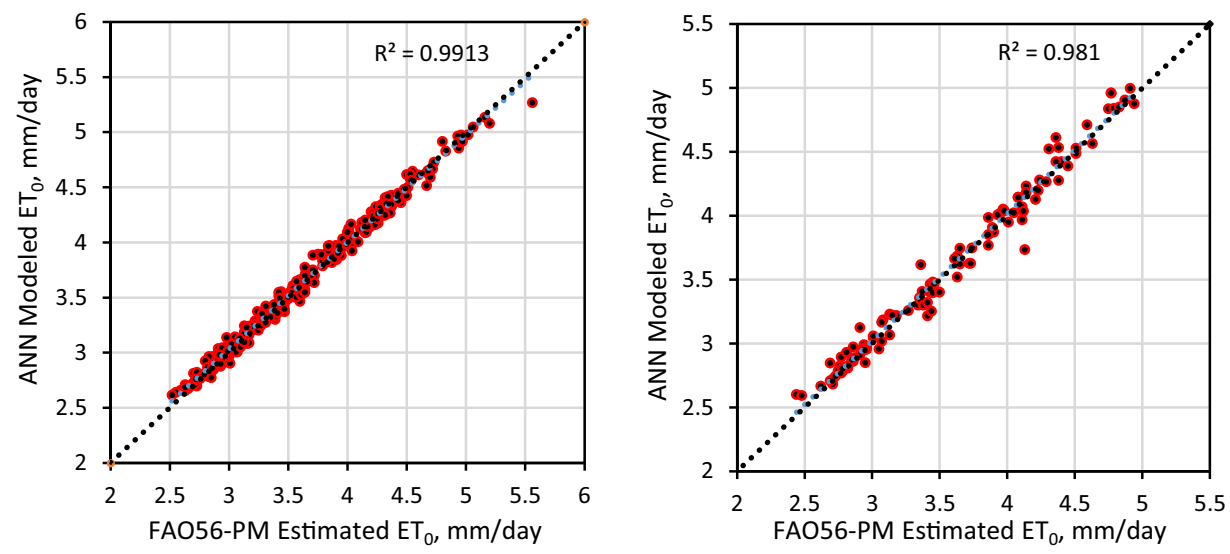

\section{Trend analysis}

The annual, seasonal, and monthly time series of $\mathrm{ET}_{0}$ for the study station were examined for the possible trend detection. The Z-statistic values of monotonic trend test were obtained through the nonparametric Mann-Kendall and Modified Mann-Kendall tests. As a precautionary step, the significant lag-1 serial correlation effect has been removed from the time series of $\mathrm{ET}_{0}$ before the trend testing. The FRI station, Dehradun observed significant annual $\mathrm{ET}_{0}$ decreases at a rate of $1.49 \mathrm{~mm} /$ year on annual basis.

Table 4 represents the trend statistics MK_Z and MMK_Z with the magnitude of the trend (Sen's slope). It 
Table 3 FAO-PM and ANN estimated mean monthly $\mathrm{ET}_{0}(\mathrm{~mm})$

\begin{tabular}{lrr}
\hline Month & $\mathrm{PM}\left(\mathrm{ET}_{0}\right)$ & \multicolumn{1}{c}{ ANN } \\
\hline Jan & 84.08 & 85.50 \\
Feb & 83.97 & 85.25 \\
Mar & 119.38 & 119.88 \\
Apr & 135.00 & 134.80 \\
May & 142.12 & 143.68 \\
Jun & 119.00 & 122.46 \\
Jul & 91.41 & 93.74 \\
Aug & 96.48 & 95.26 \\
Sep & 113.66 & 109.84 \\
Oct & 124.41 & 124.90 \\
Nov & 101.23 & 100.55 \\
Dec & 90.10 & 90.68 \\
Annual & 1300.85 & 1306.55 \\
\hline
\end{tabular}

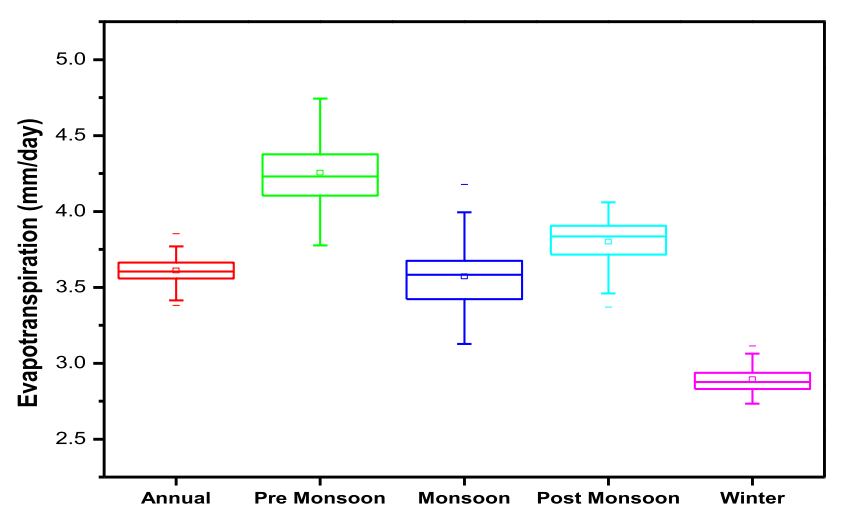

Fig. 3 Box plots for the annual and seasonal $\mathrm{ET}_{0}$

can be observed from the Table 4 that the FRI station, Dehradun is showing an increasing trend in the month of March, and a decreasing trend during June to November, except August, with more than $90 \%$ significance. The monsoon and post-monsoon season are witnessing the falling $\mathrm{ET}_{0}$ trend at a rate of 1.03 and $0.51 \mathrm{~mm} /$ year with a significance level of 95 and $99 \%$, respectively, whereas the winter and pre-monsoon seasons are not having any trends. Overall, the station is supporting a decreasing trend in the $\mathrm{ET}_{0}$ at $95 \%$ significance level with the rate of $1.49 \mathrm{~mm} /$ year on annual basis.

\section{Conclusion}

Correct estimation of evapotranspiration is prerequisite for the precise planning and management of irrigation schemes, hydrological modeling, groundwater recharge, crop performance, and land use planning, etc., and it became much more important in regions of arid and
Table 4 The trend statistics MK_Z and MMK_Z with the magnitude of the trend

\begin{tabular}{lcccr}
\hline ET series & MK_Z & MMK_Z & Slope $Q$ & \multicolumn{1}{l}{$B$} \\
\hline Jan & -0.70 & -1.00 & -0.07 & 85.699 \\
Feb & -1.33 & -1.33 & -0.14 & 86.870 \\
Mar & $2.70^{* *}$ & $2.70^{* *}$ & 0.37 & 107.635 \\
Apr & 0.31 & 0.46 & 0.05 & 130.768 \\
May & -0.61 & -0.61 & -0.14 & 146.940 \\
Jun & $-1.65+$ & $-1.65+$ & -0.50 & 130.050 \\
Jul & $-2.11^{*}$ & $-2.11^{*}$ & -0.31 & 101.525 \\
Aug & -1.63 & -1.63 & -0.28 & 103.609 \\
Sep & $-2.12^{*}$ & $-2.12^{*}$ & -0.30 & 121.050 \\
Oct & $-2.54^{*}$ & $-2.53^{*}$ & -0.28 & 133.734 \\
Nov & $-2.73^{* *}$ & $-2.73^{* *}$ & -0.20 & 108.000 \\
Dec & -0.27 & -0.27 & -0.03 & 89.482 \\
Annual & $-2.81^{*}$ & $-2.18^{*}$ & -1.49 & 1347.097 \\
Winter & -1.33 & -0.90 & -0.20 & 172.420 \\
Pre-monsoon & 0.71 & 0.70 & 0.27 & 383.981 \\
Monsoon & $-2.60^{*}$ & $-2.43^{*}$ & -1.03 & 453.393 \\
Post-monsoon & $-2.85^{* *}$ & $-2.53^{*}$ & -0.51 & 333.695 \\
\hline
\end{tabular}

Significance levels: $+90 \%$; $95 \%$; * 99\%

semiarid zones. However, it is difficult to obtain precise field measurement due to complex nature of the process itself, spatial variability, atmospheric instability, etc. There are numerous methods of computing ET, but the PenmanMonteith (PM) equation which provides the most reliable results for the estimates of reference evapotranspiration $\left(\mathrm{ET}_{0}\right)$ in most of the regions and for varied weather condition, has been adopted by Food and Agriculture Organization (FAO). In the present study, performance evaluation and comparison of simulated $\mathrm{ET}_{0}$ by FAO56 $\mathrm{PM}$ and an ANN model with single layer feed forward back propagation algorithm has been carried out. Temperature (Min., Max., and Avg.), relative humidity (Min. and Max.), average wind speed, sunshine hours and rainfall data from the meteorological monitoring station located in FRI, Dehradun on monthly basis for a period of 34 years (1980-2013) were used as inputs to predict $\mathrm{ET}_{0}$.

The ANN models for this study were developed in neural network (nn) module of MATLAB software. The basic model architecture was optimized in term of training algorithms and number of neurons in the hidden layer of the model. Six algorithms have been tested for training the neural network, followed by evaluation of the model performance by varying the number of neurons from 1 to 10 in the hidden layer. Developed model has been evaluated using various performance indices, viz. coefficient of correlation ( $r$, MSE, RMSR and NSE. Further, the trend analysis and magnitude of trend of $\mathrm{ET}_{0}$ has been carried out using MK and MMK testing methods. 
Highest value of coefficient of correlation between ANN modelled and FAO56 PM estimated $\mathrm{ET}_{0}$ was found 0.993 and 0.956 during training and validation, respectively. Which shows the good agreement between observed and estimated $\mathrm{ET}_{0}$. The ANN model with "trainlm" algorithm with nine neurons was found best for simulating the $\mathrm{ET}_{0}$ among the all iteration. In view of the $\mathrm{ET}_{0}$ trends, the study concludes that the FRI station Dehradun is experiencing the falling trend in last 34 years at the rate of $1.49 \mathrm{~mm} / \mathrm{year}$ at a significance level of $90 \%$. The modeling approach presented in this paper demonstrated the potential of the predictive power of the ANN architecture.

Open Access This article is distributed under the terms of the Creative Commons Attribution 4.0 International License (http:// creativecommons.org/licenses/by/4.0/), which permits unrestricted use, distribution, and reproduction in any medium, provided you give appropriate credit to the original author(s) and the source, provide a link to the Creative Commons license, and indicate if changes were made.

\section{References}

Ajmera TK, Goyal MK (2012) Development of stage-discharge rating curve using model tree and neural networks: an application to Peachtree Creek in Atlanta. Expert Syst Appl 39(5):5702-5710

Allen RG, Pereira LS, Raes D, Smith M (1998) Crop evapotranspiration: guidelines for computing crop requirements. FAO Irrigation and Drainage Paper No. 56, FAO Rome, Italy

Baba APA, Shiri J, Kisi O, Fard AF, Kim S, Amini R (2013) Estimating daily reference evapotranspiration using available and estimated climatic data by adaptive neuro-fuzzy inference system (ANFIS) and artificial neural network (ANN). Hydrol Res 44(1):131-146

Basistha A, Arya DS, Goel NK (2009) Analysis of historical changes in rainfall in the Indian Himalayas. Int J Climatol 29:555-572

Doğan E (2008) Reference evapotranspiration estimation using adaptive neuro-fuzzy inference systems. Irrig Drain 58(5):617-628

Goyal MK, Bharti B, Quilty J, Adamowski J, Pandey A (2014) Modeling of daily pan evaporation in sub tropical climates using ANN, LS-SVR, Fuzzy Logic, and ANFIS. Expert Syst Appl 41(11):5267-5276

Hagan MT, Menhaj MB (1994) Training feedforward networks with the Marquardt algorithm. IEEE Trans Neural Netw 5(6):989-993

Hamed KH, Rao AR (1998) A modified Mann-Kendall trend test for autocorrelated data. J Hydrol 204:182-196

Hirsch RM, Slack JR, Smith RA (1982) Techniques of trend analysis for monthly water quality data. Water Resour Res 18(1):107-121

Kendall MG (1962) Rank correlation methods, 3rd edn. Hafner Publishing Company, New York

Kendall MG, Stuart A (1961) The advance theory of statistics, 2nd edn. Hafner Publishing Co, New York

Keskin ME, Terzi O (2006) Artificial neural network models of daily pan evaporation. J Hydrol Eng 11(1):65-70
Kim S, Kim HS (2008) Neural networks and genetic algorithm approach for nonlinear evaporation and evapotranspiration modeling. J Hydrol 351:299-317

Kisi O (2006a) Evapotranspiration estimation using feed-forward neural networks. Nord Hydrol 37(3):247-260

Kisi O (2006b) Generalized regression neural networks for evapotranspiration modelling. Hydrol Sci J J Des Sci Hydrol 51(6):1092-1105

Kumar M, Raghuwanshi NS, Singh R, Wallender WW, Pruitt WO (2002) Estimating evapotranspiration using artificial neural network. J Irrig Drain Eng ASCE 128(4):224-233

Kumar M, Raghuwanshi NS, Singh R (2011) Artificial neural networks approach in evapotranspiration modeling: a review. Irrig Sci 29(1):11-25

Kumar D, Pandey A, Sharma N, Flügel WA (2015) Evaluation of TRMM-precipitation with rain-gauge observation using hydrological model J2000. J Hydrol Eng E5015007. doi:10.1061/ (ASCE)HE.1943-5584.0001317

Mann HB (1945) Nonparametric tests against trend. Econometrica 13:245-259

MATLAB (Mathwork) online reference manual. https://in. mathworks.com/help/nnet/ref/trainlm.html?requestedDomain= www.mathworks.com. Accessed 15 Dec 2016 [online]

Melesse AM, Ahmad S, McClain ME, Wang X, Lim YH (2011) Suspended sediment load prediction of river systems: an artificial neural network approach. Agric Water Manag 98(5):855-866

Moriasi DN, Arnold JG, Van Liew MW, Bingner RL, Harmel RD, Veith TL (2007) Model evaluation guidelines for systematic quantification of accuracy in watershed simulations. Trans ASABE 50(3):885-900

Odhiambo LO, Yoder RE, Yoder DC, Hines JW (2001) Optimization of fuzzy evapotranspiration model through neural training with input-output examples. Trans ASAE 44(6):1625-1633

Parasuraman K, Elshorbagy A, Carey SK (2007) Modelling the dynamics of the evapotranspiration process using genetic programming. Hydrol Sci J 52(3):563-578

Rahimikhoob A (2010) Estimation of evapotranspiration based on only air temperature data using artificial neural networks for a subtropical climate in Iran. Theor Appl Climatol 101(1-2):83-91

Sen PK (1968) Estimates of the regression coefficient based on Kendall's tau. J Am Stat Assoc 63:1379-1389

Shamshirband S, Amirmojahedi M, Gocić M, Akib S, Petković D, Piri J, Trajkovic S (2015) Estimation of reference evapotranspiration using neural networks and cuckoo search algorithm. J Irrig Drain Eng 142(2):04015044

Sudheer KP, Gosain AK, Ramasastri KS (2003) Estimating actual evapotranspiration from limited climatic data using neural computing technique. J Irrig Drain Eng ASCE 129(3):214-218

Trajkovic S, Todorovic B, Stankovic M (2003) Forecasting of reference evapotranspiration by artificial neural networks. J Irrig Drain Eng ASCE 129(6):454-457

Xu CY, Gong LB, Jiang T, Chen DL, Singh VP (2006) Analysis of spatial distribution and temporal trend of reference evapotranspiration and pan evaporation in Changjiang (Yangtze River) catchment. J Hydrol 327:81-93

Zanetti SS, Sousa EF, Oliveira VPS, Almeida FT, Bernardo S (2007) Estimating evapotranspiration using artificial neural network and minimum climatological data. J Irrig Drain Eng ASCE 133(2):83-89 